\title{
'Developing an App Could Be the Wrong Place to Start': User Reflections and Ideas about Innovation in Municipal Substance Abuse Services
}

\author{
Vidar Bakkeli* \\ Work Research Institute, Oslo Metropolitan University \\ Fafo Institute for Labour and Social Research \\ Email: Vidar.Bakkeli@oslomet.no
}

*corresponding author

\author{
Arne Backer Grønningsæter \\ Fafo Institute for Labour and Social Research \\ Email: arne.groenningsaeter@fafo.no
}

\begin{abstract}
Introduction: There has been an increased focus on the search for innovative ways to use technology to improve public welfare services. However, this focus has been less apparent among municipal substance abuse follow-up and aftercare services. Historically, this is a field that has had weak user involvement. Therefore, we have explored user ideas and reflections on whether and how technological innovation can improve these services.
\end{abstract}

Method: We conducted four group sessions with a total of 14 users of substance abuse follow-up services (five women and nine men) in the southern part of Norway in June of 2014 and February of 2016.

Results: The users who participated in the study pointed out that face-to-face interaction with service practitioners is an important dimension of these services. Some expressed fear that more technology might lead to services that are less relational or more standardized and that such developments might lead to reduced availability. They pointed out that enhancing individualization, continuity and service collaboration might be more important than prioritizing technology-oriented innovation. Nevertheless, the users viewed technology as positive and useful when it improves service accessibility and communication between service providers and users. More generally, the data also 
shed light on users' service experiences. The analysis of these data shows that access to support from peers who have had user experiences was found to be particularly valuable.

Discussion: We contribute to the literature on co-production and user involvement by highlighting user perspectives on the risks, uncertainties and possibilities for the use of new technologies in service delivery. Based on these findings, we develop the 'coproduction triangle'. In this model, the relationship between the service provider and the user is expanded to include skilled peers as a third actor.

Keywords: User involvement, co-production, technology, follow-up care, addiction, peer support

\section{Introduction}

In this study, we explore whether and how technology in a broad sense can improve local-level services, specifically substance abuse follow-up and aftercare. Technology is rapidly changing society and social relations, and in Norway, as in many other countries, there is an ongoing shift in public services towards digitalization and the increased use of new technologies for service delivery and development. Such changes are taking place across all sectors, including social benefits and activation services, health care, elderly care, the disability field and education (Lindgren, Madsen, Hofmann, \& Melin, 2019; Pollitt, 2010).

However, in the area of municipal follow-up and aftercare for drug use, alcohol and addiction, less attention has been paid to service innovation and the potential implementation of new technological solutions to existing problems. This type of care and follow-up work must address many unique challenges and is particularly difficult to manage and provide (Norwegian Ministry of Health and Care Services, 2015). Mortality rates due to overdose in Norway are among the highest in Europe (EMCDDA, 2017, p. 78), and recovery from drug and alcohol dependence is a long, difficult and complex process. For these reasons, there is a need for more research on user perspectives and the potential for service improvement.

In recent years, user involvement in service design, development and delivery has moved, in general, 'from margin to mainstream' in both research and policy fields (Barnes \& Cotterell, 2013). Since users have direct experience with the services they receive, they have important insights into how these services work, how to improve them and what new services could be introduced 
(Magnusson, 2003). Their involvement can also empower them and lead to positive effects on their recovery efforts (Crawford et al., 2002).

Therefore, in order to advance research developments in the field of substance abuse care, we set out to examine: (1) users' views of and experiences with their local follow-up services and (2) users' views and ideas concerning some of the new ways in which technology can be implemented to improve local services. In the analysis of our findings, we drew on concepts from the coproduction literature (Osborne, Radnor, \& Strokosch, 2016). We organized four group sessions of 14 participants, all users of municipal follow-up and aftercare services. We conceptualized these sessions as 'pockets of co-production' (Wilkinson \& Wilkinson, 2018, p. 6) in which knowledge production can take place through interactions between service users and us as researchers. The central aim of these sessions was to create an arena where users could generate, discuss and reflect on new ideas for service development. While we came to these sessions with a sense of optimism with respect to the use of technology, we found that the service users had a more critical approach to service development and technological innovation.

\section{Co-Production and Innovation}

In recent years, co-production has become increasingly popular in the contexts of policymaking, research and governance in many countries (Needham, 2008; Osborne et al., 2016; Voorberg, Bekkers, \& Tummers, 2015). Co-production has been conceptualized in many ways, but it can generally be defined as the voluntary or involuntary involvement of public service users in any of the design, management, delivery and/or evaluation of public services' (Osborne et al., 2016, p. 639). Osborne et al. (2016, p. 641) emphasize that services are 'intangible processes, not concrete products' and that value for the user is created through interactions with service practitioners. Municipal services providing follow-up and aftercare are based on a form of social work characterized by co-production; positive social results cannot be achieved without the direct involvement of service users (Parpan-Blaser \& Hüttemann, 2010).

In the literature on co-production, technology and public services, there is a focus on the positive impact of digital technologies. For instance, it is maintained that technology can enhance co-production by creating new forms of social interaction through which users can contribute to service delivery (e.g. through social media). The belief is that this leads to higher participation and 
engagement (Meijer, 2012) and the creation of new opportunities for participation (Lember, 2018; Lember, Brandsen, \& Tõnurist, 2019; Noveck, 2015). However, as Lember et al. (2019, p. 1666) note, there is considerable 'techno-optimism' in the field, with most research highlighting the benefits and ignoring the potential risks, uncertainties and unintended consequences of new technologies. Little research has focused on these aspects, so there is a need for more knowledge about both the potential advantages and risks of pursuing technology as a means to improving public services for vulnerable groups.

The co-production literature generally focuses on interactions between service providers and service users (Verschuere, Brandsen, \& Pestoff, 2012; Voorberg et al., 2015). We build on this understanding of co-production in our analysis on user experiences with services. We also explore another dimension of coproduction, namely the interactions between users and researchers - in other words, users involved in research (Beresford, 2013; Cairns \& Nicholls, 2018; Trivedi \& Wykes, 2002). According to Beresford (2013), a main argument supporting user involvement in research is that users have important experiential knowledge derived from direct experiences that are relevant to the research subject; consequently, their involvement will improve the quality of the research. This involvement can also be beneficial insofar as it empowers users and positively affects their beliefs about recovery.

The degree of user involvement in research can vary widely, and user involvement can mean a lot of different things (Beresford, 2013, p. 142). For example, users can be involved in only a few stages of the research process or throughout all phases, from the first step of defining the research question to the final step of publishing the findings. In our study, we aimed to create what Wilkinson and Wilkinson (2018, p. 6) call 'pockets of co-production' by establishing sessions in which users could generate, discuss and reflect on ideas in conversation and through interactions with us as researchers. In contrast, a more 'full-fledged' co-production approach would have involved the users in several or all phases of the research, such as in developing research aims and objectives, gathering data, conducting the analysis, writing articles and other activities.

An innovation process can typically be divided into four phases: (1) exploration, (2) creation, (3) reflection and (4) implementation. Exploration involves understanding the situations of the service users and stakeholders within a particular context. Creation entails developing new solutions, visions and ideas while imagining alternative futures grounded in the knowledge and insight 
obtained from the first phase. Reflection consists of getting feedback, testing out ideas and discussing design changes. Finally, implementation involves introducing the innovation (a product, service or technology) in a given context (Forshaug, 2015; Stickdorn \& Schneider, 2012). In this study, we have focused on the first two phases of exploration and creation.

The study employed a broad understanding of technology, although we focused primarily on digital technologies or information and communication technologies (ICT). We wanted to avoid narrow definitions in order to promote the creativity and imagination of the workshop participants. Since digital technologies are developing at such a rapid pace, it is generally difficult to define and categorize them in great detail (Lember et al., 2019, p. 1669). Following insights from science and technology studies and innovation studies, we understand technology as tethered 'not just to a device in isolation, but also to forms of knowledge, skill, diagrams, charts, calculations and energy which make its use possible' (Barry, 2001, p. 9; Pollitt, 2010, p. 33). Technologies have social and human elements and are part of wider networks. This broad understanding highlights the integration among technology, social practices and political, organizational and economic factors (Sismondo, 2010).

\section{User Involvement and New Technologies in Substance Abuse Services}

The international literature indicates that there is significant ambiguity regarding systemic user involvement in the field of substance abuse treatment (Barnes \& Cotterell, 2013; Crawford et al., 2003; Crawford et al., 2002; King, 2011; Patterson et al., 2009; Patterson, Weaver, \& Crawford, 2010; Schulte, Moring, Meier, \& Barrowclough, 2007). Thus, there is a need for more clearly defined roles for both service users and professionals as well as increased competency in strengthening user involvement.

In the Norwegian context, Askheim (2009) and others have pointed to the considerable distance between (1) policy ideals and the rhetoric of user involvement and (2) the realities of actual user involvement in the substance abuse field. The government has also acknowledged that there has been a lack of systematic user involvement at both the individual and system levels (Norwegian Ministry of Health and Care Services, 2015, pp. 16-17).

Several studies have found that user involvement can be difficult in practice. In one study, Aasmundsen and Sagvaag (2011) interviewed 15 service users about their experiences with service development, and they generally reported 
negative experiences. They felt that they had been stigmatized and negatively labelled and that their views had not been taken seriously. User involvement has also been an important focus of several projects related to the development of municipal social service offices (Johannessen \& Eide, 2015; Slettebø, Brodtkorb, \& Dalen, 2012). Slettebø et al. (2012) found that when establishing collaborative projects and arenas for dialogue, important factors for user involvement include recognition of user competency, involving users from the start of projects, service practitioners' relational skills and training and competency-building.

There is also a growing international body of literature concerning user involvement in and innovative uses of technologies for local-level substance abuse services. In one qualitative study from West Ireland, Van Hout and McElrath (2012) highlight that the involvement of service users in the development of treatment and rehabilitation pathways can improve the awareness of service provision in local areas, increase empowerment among service users and strengthen local partnerships. They recommend the implementation of Internet user forums and support networks as concrete ways of improving treatment services and strengthening service user involvement. In another study, Owens et al. (2011) focus on the involvement of service users in the development of a text messaging intervention service aimed at reducing self-harm in the United Kingdom. In this case, the researchers held a series of participatory workshops with service users and clinicians. The study found that working with service users is important for uncovering unmet needs and preferences and that such collaborations increase the chances of developing solutions that are 'safe, usable, clinically effective and appropriate to cultural context' (Owens et al., 2011, p. 292). However, they also found that involving service users in development processes requires flexibility and openness to uncertainty.

Until recently, little work had been done concerning the use of technology in Norwegian local-level follow-up services in the substance abuse field. However, the Norwegian journal Rus og samfunn published an issue in 2016, which focused on welfare technology in substance abuse services (Renland, 2016). One of the articles describes a project in the Kristiansand municipality in which ICT tools were used in municipal services (Haugjord \& Wivestad, 2016). The project included tools for collecting feedback from service users for service providers and rapid mental health diagnosis. Haugjord and Wivestad then stress the need to involve both service users and providers in the development process from the onset. In another article, Bjelland, Solheim, and Rørendal 
(2016) present a programme for cannabis withdrawal, and a third article covers challenges linked to health applications (apps), such as privacy and security (Meisingset, 2016).

\section{The Norwegian Service Context}

In Norway, four regional health authorities are responsible for specialist treatment of drug and alcohol addiction, while municipalities are responsible for providing outreach services, community teams and follow-up services from specialist health services or in prison. The primary tasks of municipal services include helping out with issues such as work, housing, finances and leisure activities, and individual follow-up services and counselling are key elements of providing such assistance. There is significant heterogeneity in terms of how municipal welfare services, including substance use treatment services, are organized, with the most common set up being a specific unit that provides both substance abuse follow-up services and mental health services (Dyrstad \& Ose, 2014).

However, providing substance abuse follow-up care is not necessarily easy or straightforward. As a group, service users with drug and alcohol addiction issues have a diverse set of problems related not just to addiction but also to physical or mental health issues, social issues and finances. They face considerable stigmatization and marginalization in many social contexts, and many have been met with a lack of respect by those working in the welfare system (Antonsen, 2008).

User involvement is a central policy goal in the Norwegian policy context. More specifically, the Norwegian National Action Plan on Alcohol and Drugs states that user involvement is the first of five goals to 'ensure genuine user influence through free treatment choice, more user-driven solutions and greater participation in the design of services' (Norwegian Ministry of Health and Care Services, 2015 , p. 6). A central part of this plan is to increase funding to municipalities in order to improve services. 


\section{Method}

\section{Research Design}

Our study was based on a series of focus group sessions with current and former substance users in four municipalities in the southern part of Norway. We wanted to casually open these sessions to user reflections and the sharing of views concerning municipal follow-up services. We also wanted to create constructive discussion and idea generation regarding new solutions and improved services, with an emphasis on the innovative use of technology.

To achieve these aims, we combined a relatively traditional focus group interview approach with 'brainstorming' and idea generation. Each session lasted between 2.5 and 3 hours. The first part of each session was structured in a focus group format, during which we asked questions and then encouraged reflection and discussion with the participants. The themes of concern were the participants' experiences with local municipal services, challenges in using these services, experiences with user involvement and ideas on how technology can be used to create improved services. In the second part of each session, we handed out Post-it notes and A4 size paper so that the participants could write down the ideas emerging from the sessions, along with other ideas they might have had. In the last part of each session, we reviewed and discussed these ideas.

Two researchers were present for each session, one of whom had the main responsibility of taking notes. We tried to create a relaxed and open atmosphere so that the participants could feel at ease. We had pizza delivered, served snacks and drinks and made sure to take frequent breaks. Our impression was that most participants appreciated the opportunity to share their thoughts and perspectives. The atmosphere was a bit tense at the beginning of some of the sessions, and the group dynamics varied between the meetings, but our overall impression was that we managed to create a relaxed setting in which most participants felt free to share their ideas and reflections. As researchers, we tried to find a balance between playing an active role in the conversations (e.g. by directly asking questions or trying out reflections) and serving as facilitators of user reflection and idea development.

Approval for the project was granted by the Norwegian Ombudsman for Research at the Norwegian Centre for Research Data in April of 2014. The project was part of a wider project consortium, with the University of Agder 
serving as project leader. Between 2014 and 2017, several workshops and seminars were held to discuss project progress and paper drafts. Academics, researchers and user representatives participated in these discussions.

\section{Recruiting Participants}

The participants in the first three sessions were recruited through local service providers in three different municipalities. Those in the fourth session were recruited with the help of a user organization. In the early phase of the project, we met with municipal social workers to gain access to participants and better understand the local contexts.

Our selection criteria for the municipalities were related to the overall framing and localization of the research project. The main project leader, the University of Agder, is located in the southern region of Norway, so it made sense for us to choose municipalities in the same region. The main criteria were that the municipalities should have a focus on service development and user involvement and that they would agree to help us recruit session participants. Three of the sessions were conducted in midsized municipalities, while the fourth took place in a larger city municipality in the southern region.

A total of 14 service users (five women and nine men) participated in four group sessions. Three sessions took place in June of 2014, while the fourth was arranged in February of 2016.

Table 1. Group Sessions and Participants

\begin{tabular}{llll} 
Session date & $\begin{array}{l}\text { Number of } \\
\text { participants }\end{array}$ & Women & Men \\
\hline 10.6 .2014 & 3 & 1 & 2 \\
11.6 .2014 & 3 & 1 & 2 \\
17.6 .2014 & 3 & 1 & 2 \\
2.2 .2016 & 5 & 2 & 3 \\
\hline
\end{tabular}

Initially, our aim was to recruit only younger people (aged 18 to 25). The main argument for this was that younger people are more familiar with social media and new technologies. Following dialogue with the municipalities, however, we chose to include some older participants, as there was a risk of non-attendance or withdrawal on the day of the sessions. Altogether, 11 out of 14 participants were between 18 and 25 years of age, and 3 participants were between 30 and 
50 years of age. Overall, we found that this wide age gap was a strength, as it resulted in a broad spread of data.

Prior to participation, potential participants received a document with information about the project. It contained information about the research aims and objectives as well as informed consent. It also stated that participation was voluntary and that participants could withdraw at any time. It further stipulated that all participants were assured of confidentiality and that they would not be identifiable in project publications. We reiterated this information at the beginning of each session.

\section{Data Analysis}

Our main data material consists of extensive notes, which we took during each session, as well as the users' ideas, which were written down. The data also included some of our field notes containing our own reflections about the sessions. The sessions were not audio recorded. While in hindsight we think that recordings would have been advantageous, we also think that the choice not to do so contributed to the relaxed atmosphere we wanted in the sessions, since some participants might have reacted negatively to recording their conversations.

We conducted a thematic analysis of the data material, in line with the approach outlined by Braun and Clarke (2006). This involved first becoming familiar with the data, labelling the data with initial codes, searching for broader themes to organize the codes and then reviewing and developing the themes further. In our analysis, the codes included 'life situation', 'challenges with services', 'peer work', 'experiences with user involvement', 'technology-oriented ideas' and 'general ideas'. We also divided technology-related ideas into three categories: 'information', 'communication' and 'organizing daily life'. These codes were sorted into broader themes. Four themes emerged as most important: (1) user experiences and challenges with current services; (2) views on service development and technology; (3) the importance of peer support and (4) specific technology-oriented ideas for improving services.

\section{Findings}

Based on our analysis of the four sessions, we will now review the user reflections on technology and service development. The presentation of the 
findings is structured according to the four themes developed in the data analysis.

\section{User Experiences with Services}

The participants emphasized the importance of individualization, availability and continuity while also identifying issues with coordination. We present these views briefly to give a sense of how the users conceptualized these services in a more holistic way. Individualized services, with the user being the central focus, embody important values in local follow-up services, but these ideals can be difficult to implement in daily service delivery (Dyrstad \& Ose, 2014). An important aspect of individualization is treating users with respect while demonstrating some curiosity about their individual situations. The users had many stories that contradicted this ethos, as illustrated by the following quotes:

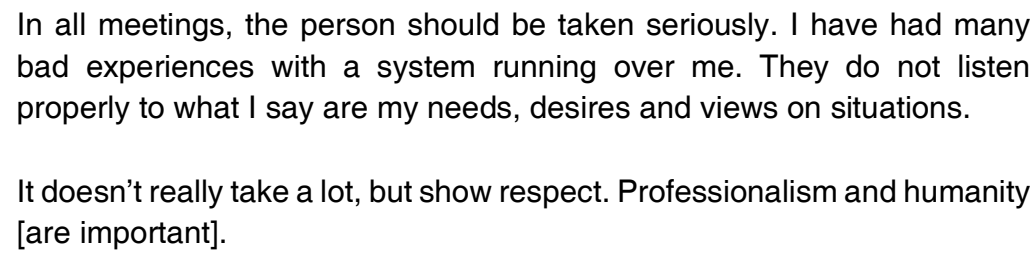

These statements point to the need for social workers to listen attentively to service users. The study participants, such as those quoted above, generally expressed that they had experienced a lack of user involvement and felt that they were not being heard. This was the case for both their individual situations and in relation to their involvement on a more systemic level. These are important conditions for establishing active co-production in daily service interaction. However, there were some differences in opinion; for example, one participant with a background in user representation had more experience in representing the user's voice in different arenas.

Participants were also concerned about lack of access to services. In their experience, social workers were often hard to reach:

\footnotetext{
It is very demotivating when you want to stop using drugs and those who should support you are not available. You end up in a queue on a call centre [line] when you need contact with a social worker.

It does not help to have an appointment with the social worker three weeks ahead if you are desperate for drugs. You need help at that very moment.
}

The users expressed the need for greater flexibility and increased capacity in the services they received. Another concern was related to the fact that the 
relationships between the users and service providers were characterized by high personnel turnover rates and instability. The following transcript of an exchange between two users sums up this view:

User A: It's important [to have] continuity and stability in relation to the services. We have many experiences of feeling insecure in meetings with the system. So it's important with stability, that people are not frequently replaced.

User B: Now they have a new guy in. It is working out well, but he will quit in June. This makes me panic. They are the ones I go to when I need help.

User A: It's very tiring to explain the same things to new people all the time.

User B: Yeah, I had to explain again and again about things that were already agreed upon.

Consequently, due to staff turnover, these users had many experiences of repeatedly telling their life stories to new people or having to start all over in building relationships with new supervisors. While turnover in these services is unavoidable, it is important to be aware of the costs on the user side.

The participants were also concerned about coordination and cooperation between services. Many had had good experiences with one form of collaboration, namely responsibility group meetings (ansvarsgruppemøter). Such meetings function as an important tool for the coordination of services around each user. In these meetings, professionals from different relevant services meet with the user in the same room to discuss goals, progress and how to resolve issues together. A coordinator has a central role in organizing this type of meeting. This arrangement can be conceptualized as an ongoing and institutionalized form of co-production, emphasizing user voice, participation and integration of services in the local welfare system (Osborne et al., 2016, p. 647). Overall, our study participants were quite positive about this process and underlined the importance of mutual trust in making it work. As one participant said,

When you ask for help, you must get a responsibility group (ansvarsgruppemøter), which follows you throughout, and trust is crucial here. There should not be any time limit to receive follow-up.

However, several of our participants alluded to the need for better coordination. Research has shown that coordinated aftercare and follow-up treatment are a critical element in the long-term recovery of substance users (Dahle \& Iversen, 2011; Nordfjaern, Rundmo, \& Hole, 2010). In fact, there has been considerable 
critique in the Norwegian context of the lack of coordination between actors receiving substance abuse treatment and the municipalities responsible for follow-up and aftercare (Norwegian Ministry of Health and Care Services, 2015, p. 25). Our study participants also highlighted these issues as crucial. Users are in a vulnerable situation when they leave treatment, often left with a weak network and high levels of insecurity. As another participant said,

[There] should be close follow-up from the NAV [Norwegian Labour and Welfare Administration] office and other service providers. We need support when we leave treatment and enter follow-up services. This could be either from a social worker or from a peer/coordinator.

While certainly essential, this process is challenging, as it requires coordination between municipalities and specialist treatment services. There is also a need for some level of coordination among different municipal actors, such as substance abuse follow-up services and the local Labour and Welfare Administration office (NAV).

\section{Views on Technology and Service Development}

Having established this range of challenges as a background to our discussion, we move on to explore how technology can contribute to resolving the issues identified with the services. Looking back, it is quite clear to us that, initially, we had some preconceived and over-optimistic notions about the potential application of technology in the field of substance abuse treatment. However, several of the study participants had doubts about this focus and challenged us in the sessions. According to one participant who was especially clear on this, 'To develop an app can be the wrong place to start'. This participant was sceptical about adopting such a narrow focus on technology, pointing out that there were other more pressing issues. In contrast, the participants introduced what can be referred to as a more holistic approach, where human relationships are the primary focus. They were concerned about the importance of face-toface meetings with real people in the services and developing meaningful relationships. Drawing this distinction between the 'unreal', artificial online world and the real offline world is common and has been discussed in earlier studies (Angouri, 2015, p. 324; Bell, 2001). This statement from one participant in the fourth session is particularly illustrative of this point:

I think all the apps are very scary. You need people. There are enough apps. I meet people through my contacts. I miss people. If you need a person to talk to, it can be a bureaucrat. There is too much focus on other things than the individual. 
Many users stated that they struggled with loneliness and limited social networks; some had a history of losing touch with their families and noted that they missed meaningful daily activities. Their relationships with their social workers and their participation in social services were, therefore, very important to them. One participant wrote on a Post-it note, 'Technology must not replace the relationships between social workers and the [service] users'. Some of the service users' stories were characterized by experiences of inflexible services, which were only available during office hours; distant, overworked social workers and rigid bureaucracies with excessive paperwork and other demands. These participants also viewed ICT as part of the problem and associated it with rigid inflexibility, limited availability, cost cutting and standardization.

Another underlying reason for the scepticism regarding technology among some of the study participants was based on their telephone interactions and issues regarding website accessibility. As one participant said, 'Thinking about accessing a web page to get help makes me so stressed. I prefer to use the phone and call. The simpler, the better'. Several participants also had what they called 'phone fear', especially when they have to make a call to a public service agency. They had negative experiences relating to not getting needed help, being put on hold in endless telephone queues and not getting through to the right person in the municipality. Others pointed out that basing services entirely on mobile phones can be problematic. Many users' lifestyles are characterized by a high risk of frequently losing or selling their phone and being without a phone for long periods.

In short, we found considerable variation between the participants concerning their views on technology and how they relate to technology in their lives, with these views ranging from positive to highly negative. Consistent with the previous literature, these findings highlight the importance of grounding new solutions on specific knowledge about user preferences, needs and the different contexts in which users live their lives (see Owens et al., 2011; Van Hout \& McElrath, 2012). The findings also underline the significance of the initial exploration phase in innovation processes (Forshaug, 2015). This phase is structured around facilitating an understanding of the situation and context of service users and other actors involved. As such, this phase is especially crucial given that the other phases (creation, reflection and implementation) build on this knowledge. Strong user involvement is important in all stages, perhaps especially so in the exploration phase. 


\section{The Importance of Peers}

Several of the participants highlighted the benefits of developing relationships with peers and other helpers who have personal experiences with receiving services:

[There] should be more use of consultants with user experience. [lt is] important to see people, not just their diagnosis.

[There should be] better use of peers. [There should be] cooperation between the municipalities and organizations so that the best interests of the users are taken care of.

Discussing and sharing information with peers who understood them was described as an important experience. Our respondents saw this as both valuable in itself and as a necessary prerequisite for their empowerment. A general observation from across the sessions was that the participants were especially concerned with creating opportunities for connecting with peers. One set of ideas emerged regarding the use of social media or online discussion forums, where support groups could be formed, along with participation from user organizations. These ideas point towards the need to develop collaborative online platforms or a form of sharing economy, with peer-based activities through which participants could share experiences, information and services (Hamari, Sjöklint, \& Ukkonen, 2016).

Many of the participants seemed to think in terms of a three-way cooperative structure, where users, skilled peers and professional social workers were equal partners. This framework exhibited clear aspects of co-production, with the aim of developing stronger interactive relationships by connecting service practitioners, skilled peers and service users in new ways. This line of thinking can be illustrated as a 'co-production triangle', as shown in the figure below. 


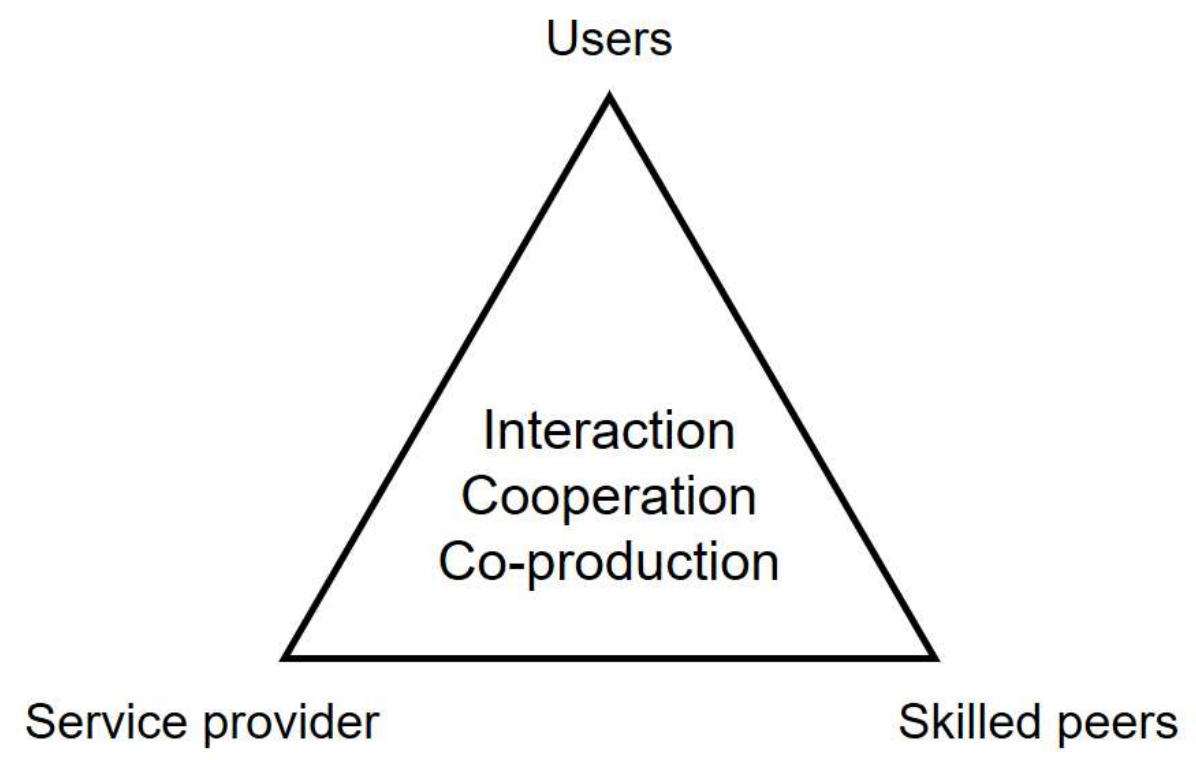

Figure 1. Co-production triangle between users, service provider and skilled peers

\title{
Specific User Ideas
}

Most of the session participants had several ideas on the ways in which ICT and other forms of technology could work to improve services or help with the management of their particular situations. In this section, we present the ideas discussed in the sessions.

\section{Chatting with social workers or having a 'chat mentor'}

One of the ideas mentioned involved communicating with social workers through text-based chatting, which can have some advantages over talking on the phone, such as an increased sense of anonymity. As one participant said,

\begin{abstract}
A channel for chatting would be experienced as safer. Sometimes, it is easier to write than to talk. Writing can lower some barriers. Many people could be helped if the barriers were lower. Some people are afraid of telephones.
\end{abstract}

The participants also pointed out that such a service should have extended opening hours, preferably $24 / 7$, as the main point would be to lower barriers for connecting with this service. One participant also mentioned the possibility of having a 'chat mentor', i.e. someone who follows you over time and provides motivation:

One could have a button to press so that it is possible to engage a supporter or a mentor. Sometimes, one only needs a person to drink coffee with. They can be linked up through an app. 
The participants also noted that a chat service connected to persons with their own user experiences (peers) would also be beneficial. Online discussion forums with these kinds of mentors could also be helpful.

\section{A Map In The 'Service Jungle'}

One problem pointed out by several participants was that while there was a considerable amount of help and many services available, information about these services remained scarce. They explained that there are many relevant services and organizations that can help, including public, non-profit, civil society and user organizations and private initiatives; however, trying to access them can be like walking through 'a jungle'. Regarding this matter, one participant said the following:

There are a lot of offers out there. What you need is a portal. It feels like there are 40 posts hanging around in nature but no map showing how to find them. Nobody has a map.

An online portal could include information about the various organizations and services and about issues pertaining to users' rights. It could provide clear, concise information and would be useful for both users and their families. Either a Web-based portal or one available through a mobile app could work here.

\section{Booking Appointments and Everyday Structure}

Many participants had problems organizing their everyday lives. Several wanted an easier way to book appointments with municipal agencies. An appointment tool with a calendar connected to the social worker's schedule would make services more transparent and accessible. Such a tool would allow participants to book appointments online when needed.

Other key issues and challenges emerging from the sessions were related to keeping track of appointments; creating a structure and sticking to it; budgeting and financial planning and following medication guidelines. One participant noted that it could be useful to have an app which integrated the different needs in terms of structure, finances and medication.

\section{Discussion}

Overall, the study participants viewed service development and technology issues in a nuanced and holistic way. During the sessions, they drew a larger picture of their service experiences and the challenges they faced in terms of 
the lack of individualization, continuity, availability and flexibility in services as well as issues with coordination and collaboration. It is clear to us that remaining cognizant of these factors is crucial when developing services in general and especially with regard to technological innovation. Issues of organization, user accessibility, technology and service content cannot be clearly viewed or effectively addressed in isolation.

We contribute to the literature on co-production and the impact of technology by pointing to the risks and uncertainties associated with technology in service delivery, as seen from the user's perspective. The participants were concerned that technology could have negative consequences on service quality; decrease the availability of social workers and supervisors; replace human relationships; be part of cost-effectiveness and budget cut strategies and lead to a more standardized bureaucracy. These views have some parallels with discussions about technology and services in the social care sector, where 'cold technology' is typically portrayed as a threat to 'warm hands' (Pols \& Moser, 2009).

Through an analysis of the empirical material, we conceptualized three different forms of co-production, namely co-production understood as regular service interaction between users and frontline employees; the 'co-production triangle' as a conceptual model for service development and sessions as 'pockets of coproduction' involving users and researchers. Regarding co-production as daily service interaction (e.g. ansvarsgruppemøter), we found that user participants were well aware that interactions between service providers and themselves form the heart of the services they rely on. They experienced challenges relating to the lack of individualization, user involvement, participation, continuity and coordination. As they reflected on the challenges faced and the potential for new technological solutions, they emphasized the importance of strengthening human relations. Technology can play a positive role if it supports existing relationships between people, such as by strengthening and facilitating access to social workers, social services and peer support.

We also present the idea of the co-production triangle as a conceptual model. Co-production models usually focus on two actors: service providers and users (Bovaird, 2007; Nabatchi, Sancino, \& Sicilia, 2017; Osborne et al., 2016). We argue that the co-production triangle represents an expansion to this idea by introducing peers as a third actor, with a mediating role between the other actors. Many participants highlighted the benefits of receiving support from peers based on their own user experiences. In this triangle, technology can be used to facilitate and strengthen relations between these three actors. 
This study was an attempt at creating 'pockets of co-production' involving service users and researchers, which take place outside regular service interaction. We believe that this approach of exploring user experiences through 'pockets of co-production' has contributed some important insights, particularly concerning user ideas for integrating digital technologies in service delivery. All the actors involved have experiences, interests and agency that need to be acknowledged, especially in the design and development of new services. The study participants stressed the importance of setting up inclusive processes when developing services.

Nevertheless, we also acknowledge the limitations of our research. First, the sessions involved a limited number of users. A research design involving a greater number of users and sessions might have provided richer empirical material. Furthermore, repeatedly engaging with users and practitioners over a longer period of time could have enabled us to achieve a better understanding of the lived experiences and local service context as well as strengthened the potential for co-production in the project. Involving service practitioners in integrated or separate sessions would also have opened up the potential for more ideas to be developed and would have strengthened the co-productive dialogue between users, service providers and researchers.

\section{Conclusion}

In this article, we presented service user perspectives and reflections on the potential of using new forms of technology to improve municipal substance abuse services, such as follow-up and aftercare. The study participants were all users of these services, and they expressed both scepticism and optimism towards new forms of technology. Some warned that technology could replace human interaction and lead to services of poorer quality. The participants were also concerned about individualization, service availability, continuity and coordination, but there was a general consensus that new uses of technology could improve services if, for example, they lead to increased availability and easier interactions with social workers or supervisors. Lastly, the participants highlighted the importance of receiving support from peers with user experiences as well as the benefits of what we call a 'co-production triangle', which includes social workers, skilled peers and users themselves.

Our findings indicate that better cooperation between users, peers with user experiences, service providers and researchers could contribute to innovation in the provision of substance abuse services. We need to expand our 
understanding of how individuals and technology can interact. The coproduction triangle could be a good starting point for further research and the exploration of new forms of co-production in this field.

\section{References}

Angouri, J. (2015). Online communities and communities of practice. In A. Georgakopoulou \& T. Spilioti (Eds.), The Routledge handbook of language and digital communication (pp. 323-338). Abingdon: Routledge.

Antonsen, E. B. (2008). Et stykke på vei, men likevel langt igjen? [On the way, but still far to go?] Tidsskrift for psykisk helsearbeid, 5(4), 345-354.

Askheim, O. P. (2009). Brukermedvirkning - kun for verdige trengende? [Service-user participation in decision-making - only for the worthy?] Tidsskrift for psykisk helsearbeid, 6(1), 52-59.

Barnes, M., \& Cotterell, P. (2013). Critical perspectives on user involvement. Bristol: The Policy Press.

Barry, A. (2001). Political machines: Governing a technological society. London and New York: Athlone Press.

Bell, D. (2001). An introduction to cybercultures. London: Routledge.

Beresford, P. (2013). From 'other' to involved: User involvement in research: An emerging paradigm. Nordic Social Work Research, 3(2), 139-148. https://doi.org/10.1080/2156857X.2013.835138

Bjelland, C., Solheim, A. K., \& Rørendal, M. (2016). Hasjavvenning på mobilen [Getting off marijuana on the mobile phone] Rus og Samfunn, 9(6), 34-37.

Bovaird, T. (2007). Beyond Engagement and Participation: User and Community Coproduction of Public Services. Public Administration Review, 67(5), 846-860. https://doi.org/10.1111/j.1540-6210.2007.00773.x

Braun, V., \& Clarke, V. (2006). Using thematic analysis in psychology. Qualitative $\begin{array}{llll}\text { Research in } & \text { 75ychology, }\end{array}$ https://doi.org/10.1191/1478088706qp063oa

Cairns, J., \& Nicholls, J. (2018). Co-production in substance use research. Drugs and Alcohol Today, 18(1), 6-16. https://doi.org/10.1108/DAT-02-2018-0002

Crawford, M. J., Aldridge, T., Bhui, K., Rutter, D., Manley, C., Weaver, T., . . Fulop, N. (2003). User involvement in the planning and delivery of mental health services: a cross-sectional survey of service users and providers. Acta Psychiatr Scand, 107(6), 410-414. https://doi.org/10.1034/j.1600-0447.2003.00049.x

Crawford, M. J., Rutter, D., Manley, C., Weaver, T., Bhui, K., Fulop, N., \& Tyrer, P. (2002). Systematic review of involving patients in the planning and development of health care. British Medical Journal, 325(7375), 1263-1265. https://doi.org/10.1136/bmj.325.7375.1263

Dahle, K. A., \& Iversen, H. H. (2011). Hva er viktig for pasienter innen rusbehandling? [What is important for patients in drug addiction treatment?] Nasjonalt kunnskapssenter for helsetjenesten.

Dyrstad, K., \& Ose, O. S. (2014). Kommunalt rusarbeid og innlemming av statlig rustilskudd $i$ den kommunale rammen [Municipal drug addiction work and inclusion of state grants in the municipal budget frame] Sintef. 
EMCDDA. (2017). European Drug Report: Trends and Developments. European Monitoring Centre for Drugs and Addiction.

Forshaug, A. K. (2015). User involvement in design of health care services. In G. Bingham, D. Southee, J. McCardle, A. Kovacevic, E. Bohemia, \& B. Parkinson (Eds.), Great expectations : design teaching, research \& enterprise : proceedings of the 17th International Conference on Engineering and Product Design Education, Loughborough Design School, University of Loughborough, United Kingdom, 3rd-4th September 2015 (pp. 226-231).

Hamari, J., Sjöklint, M., \& Ukkonen, A. (2016). The sharing economy: Why people participate in collaborative consumption. Journal of the Association for Information Science and Technology, 67(9), 2047-2059. https://doi.org/10.1002/asi.23552

Haugjord, K., \& Wivestad, A. (2016). Vår DIGITALE verden [Our digital world] Rus og Samfunn, 9(6), 30-33.

Johannessen, A., \& Eide, S. B. (2015). Evidence from social service enhancement projects: Selected cases from Norway's HUSK project. J Evid Inf Soc Work, 12(1), 7-31.

King, A. (2011). Service user involvement in methadone maintenance programmes: The 'philosophy, the ideal and the reality'. Drugs: Education, Prevention and Policy, 18(4), 276-284. https://doi.org/10.3109/09687637.2010.495098

Lember, V. (2018). The role of new technologies in co-production and co-creation. In T. Brandsen, T. Steen, \& B. Verschuere (Eds.), Co-croduction and co-creation: Engaging citizens in public service delivery (pp. 115-127). London and New York: Routledge. https://doi.org/10.4324/9781315204956-16

Lember, V., Brandsen, T., \& Tõnurist, P. (2019). The potential impacts of digital technologies on co-production and co-creation. Public Management Review, 21(11), 1665-1686. https://doi.org/10.1080/14719037.2019.1619807

Lindgren, I., Madsen, C. Ø., Hofmann, S., \& Melin, U. (2019). Close encounters of the digital kind: A research agenda for the digitalization of public services. Government Information Quarterly, 36(3), 427-436. https://doi.org/10.1016/j.giq.2019.03.002

Magnusson, P. R. (2003). Benefits of involving users in service innovation. European Journal of Innovation Management, 6(4), 228-238. https://doi.org/10.1108/14601060310500940

Meijer, A. (2012). Co-production in an information age: Individual and community engagement supported by new media. VOLUNTAS: International Journal of Voluntary and Nonprofit Organizations, 23(4), 1156-1172. https://doi.org/10.1007/s11266-012-9311-z

Meisingset, K. (2016). - Må rydde opp [- Need to sort it out]. Rus \& samfunn, 6/2016, 38-42.

Nabatchi, T., Sancino, A., \& Sicilia, M. (2017). Varieties of participation in public services: The who, when, and what of coproduction. Public Administration Review, 77(5), 766-776. https://doi.org/10.1111/puar.12765

Needham, C. (2008). Realising the potential of co-production: Negotiating improvements in public services. Social Policy and Society, 7(2), 221-231. https://doi.org/10.1017/S1474746407004174

Nordfjaern, T., Rundmo, T., \& Hole, R. (2010). Treatment and recovery as perceived by patients with substance addiction. J Psychiatr Ment Health Nurs, 17(1), 46-64. https://doi.org/10.1111/j.1365-2850.2009.01477.x 
Norwegian Ministry of Health and Care Services. (2015). The Norwegian National Action Plan on Alcohol and Drugs (2016-2020). Prop. 15S (2015-2016). Oslo: Norwegian Ministry of Health and Care Services.

Noveck, B. S. (2015). Smart citizens, smarter state. The technologies of expertise and the future of governing. Cambridge, MA: Harvard University Press. https://doi.org/10.4159/9780674915435

Osborne, S. P., Radnor, Z., \& Strokosch, K. (2016). Co-production and the co-creation of value in public services: A suitable case for treatment? Public Management Review, 18(5), 639-653. https://doi.org/10.1080/14719037.2015.1111927

Owens, C., Farrand, P., Darvill, R., Emmens, T., Hewis, E., \& Aitken, P. (2011). Involving service users in intervention design: a participatory approach to developing a textmessaging intervention to reduce repetition of self-harm. Health Expectations, 14(3), 285-295. https://doi.org/10.1111/j.1369-7625.2010.00623.x

Parpan-Blaser, A., \& Hüttemann, T. (2010). Key issues and dimensions of innovation in social services and social work. In K. Müller, S. Roth, \& M. Zak (Eds.), Social Dimension of Innovation (pp. 183-194). Prag: Linde.

Patterson, S., Weaver, T., Agath, K., Albert, E., Rhodes, T., Rutter, D., \& Crawford, M. (2009). 'They can't solve the problem without us': a qualitative study of stakeholder perspectives on user involvement in drug treatment services in England. Health \& Social Care in the Community, 17(1), 54-62. https://doi.org/10.1111/j.1365-2524.2008.00797.x

Patterson, S., Weaver, T., \& Crawford, M. (2010). Drug service user groups: Only a partial solution to the problem of developing user involvement. Drugs: Education, $\begin{array}{llll}\text { Prevention } \quad \text { and } & \text { 80licy, }\end{array}$ https://doi.org/10.3109/09687630802225495

Pollitt, C. (2010). Technological change: A central yet neglected feature of public administration. NISPAcee Journal of Public Administration and Policy 3(2), 3153. https://doi.org/10.2478/v10110-010-0003-z

Pols, J., \& Moser, I. (2009). Cold technologies versus warm care? On affective and social relations with and through care technologies. ALTER - European Journal of Disability Research / Revue Européenne de Recherche sur le Handicap, 3(2), 159-178.

Renland, A. (2016). Leder [Editorial]. Rus \& samfunn, 6/2016.

Schulte, S., Moring, J., Meier, P. S., \& Barrowclough, C. (2007). User involvement and desired service developments in drug treatment: Service user and provider views. Drugs: Education, Prevention and Policy, 14(3), 277-287. https://doi.org/10.1080/09687630701267317

Sismondo, S. (2010). The social construction of scientific and technical realities. In S. Sismondo (Ed.), An introduction to Science and Technology Studies (pp. 57-71). United Kingdom: Wiley-Blackwell.

Slettebø, T., Brodtkorb, E., \& Dalen, H. (2012). Brukernes erfaringer og syn på kollektiv brukermedvirkning [User experiences and views on collective user involvement] Fontene forskning, 12(1), 43-55.

Stickdorn, M., \& Schneider, J. (2012). This is service design thinking: Basics, tools, cases. Amsterdam: BIS Publishers.

Trivedi, P., \& Wykes, T. (2002). From passive subjects to equal partners: qualitative review of user involvement in research. The British Journal of Psychiatry, 181, 468-472. https://doi.org/10.1192/bjp.181.6.468 
Van Hout, M. C., \& McElrath, K. (2012). Service user involvement in drug treatment programmes: Barriers to implementation and potential benefits for client recovery. Drugs: Education, Prevention and Policy, 19(6), 474-483. https://www.tandfonline.com/doi/full/10.3109/09687637.2012.671860

Verschuere, B., Brandsen, T., \& Pestoff, V. (2012). Co-production: The state of the art in research and the future agenda. VOLUNTAS: International Journal of Voluntary and Nonprofit Organizations, 23(4), 1083-1101. https://doi.org/10.1007/s11266$\underline{012-9307-8}$

Voorberg, W. H., Bekkers, V. J. J. M., \& Tummers, L. G. (2015). A systematic review of co-creation and co-production: Embarking on the social innovation journey.

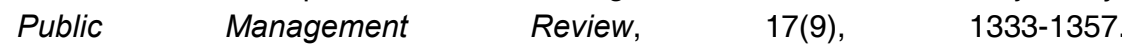
https://doi.org/10.1080/14719037.2014.930505

Wilkinson, S., \& Wilkinson, C. (2018). Researching drinking 'with' young people: A palette of methods. Drugs and Alcohol Today, 18(1), 6-16. https://doi.org/10.1108/DAT08-2017-0036 